\title{
O SATURNISMO E A QUEDA DO IMPÉRIO ROMANO*
}

\author{
Antonio Aguilera Martín ${ }^{1}$
}

\begin{abstract}
Resumo
Durante muitos anos, e de forma recorrente, alguns estudiosos da história de Roma consideraram que o saturnismo (envenenamento por chumbo) provocado pela ingestão de vinho contendo mosto, foi uma das causas principais da loucura de alguns imperadores romanos, da falta de natalidade de sua aristocracia ou, inclusive, da queda do império romano. Neste trabalho se demonstra o contrário, pois o mosto foi utilizado pelos romanos só na fabricação de vinhos de má qualidade. Portanto, precisamente o saturnismo atuou, sobretudo, dentre as camadas mais desfavorecidas da população, nunca sobre as classes altas.
\end{abstract}

\section{Palavras-chave}

Saturnismo, mosto, aristocracia romana

\section{Resumen}

Durante muchos años, y de forma recurrente, algunos estudiosos de la historia de Roma han considerado que el saturnismo (envenenamiento por plomo) provocado por la ingesta de vino conteniendo arrope, fue una de las causas principales de la locura de algunos emperadores romanos, de la falta de natalidad de su aristocracia o incluso de la caída del imperio romano. En este trabajo se demuestra lo contrario, pues el arrope fue utilizado por los romanos sólo en la fabricación de vinos de mala calidad. Por tanto, precisamente el saturnismo actuó sobre todo entre las capas más desfavorecidas de la población, nunca sobre las clases altas.

\section{Palabras clave}

Saturnismo; arrope; aristocracia romana.

\footnotetext{
* Tradução: Hélio Gustavo da Silva Andrade.

1Professor Doutor, Universidade de Barcelona, Barcelona, Espanha. E-mail: antonioaguilera@ub.edu
} 
Conheci a Pedro Paulo Abreu Funari no curso de 1989-90, sendo eu um estudante de último ano, em Barcelona. Foi anunciada uma conferência sobre grafites pompeianos dada por um professor do Brasil, a qual fui com curiosidade assistir, já que nunca pensei que alguém do Brasil se dedicasse a esta área do conhecimento. Mas, a palestra dada por Pedro Paulo me convenceu de que no Brasil, ao menos, vivia uma rara avis que estava a altura dos europeus dedicados à História Antiga. Aquela rara avis me forçou a conhecer como funciona a onomástica em língua portuguesa, pois a partir de então, Funari se tornou um dos autores que sempre tive que citar ao longo de minha carreira como pesquisador.

Entretanto, como não podia ser diferente, Funari não era uma rara avis. Após ele começaram a chegar em Barcelona alguns de seus incontáveis alunos, sendo que muitos deles posso considerar amigos (especialmente Renata Garrafoni, Claudio Carlan, Marina Cavicchioli, Lourdes Feitosa, dentre outros). E esta, talvez seja a maior conquista de Funari: ter criado uma escola de historiadores da Antiguidade no Brasil. Trata-se de uma escola que Funari foi criando com inteligência e, sobretudo, com muito esforço. Uma escola cujos membros percorreram diversos centros de investigação europeus e que contribuíram para que o estudo da História Antiga fosse algo praticado no Brasil atual.

Depois de sua primeira palestra, Funari veio a Barcelona diversas vezes, e com ele me encontrei, também, em outros lugares. Conheci, então, a pessoa que Funari era. Um de nossos encontros mais cativantes foi uma viagem que realizamos juntos de Barcelona para Klagenfurt, na Aústria, com o intuito de participar de um congresso sobre epigrafia.

Fomos de avião, juntamente com José Remesal y Piero Berni, partimos de Barcelona com destino a Veneza e de lá cruzamos os Alpes em um carro alugado, pois deste modo economizaríamos. No caminho de volta a Veneza dormimos em Bruneck, na casa de um autêntico tirolês e velho amigo de Remesal, o professor H.J. Ulb, da Universidade de Viena. 


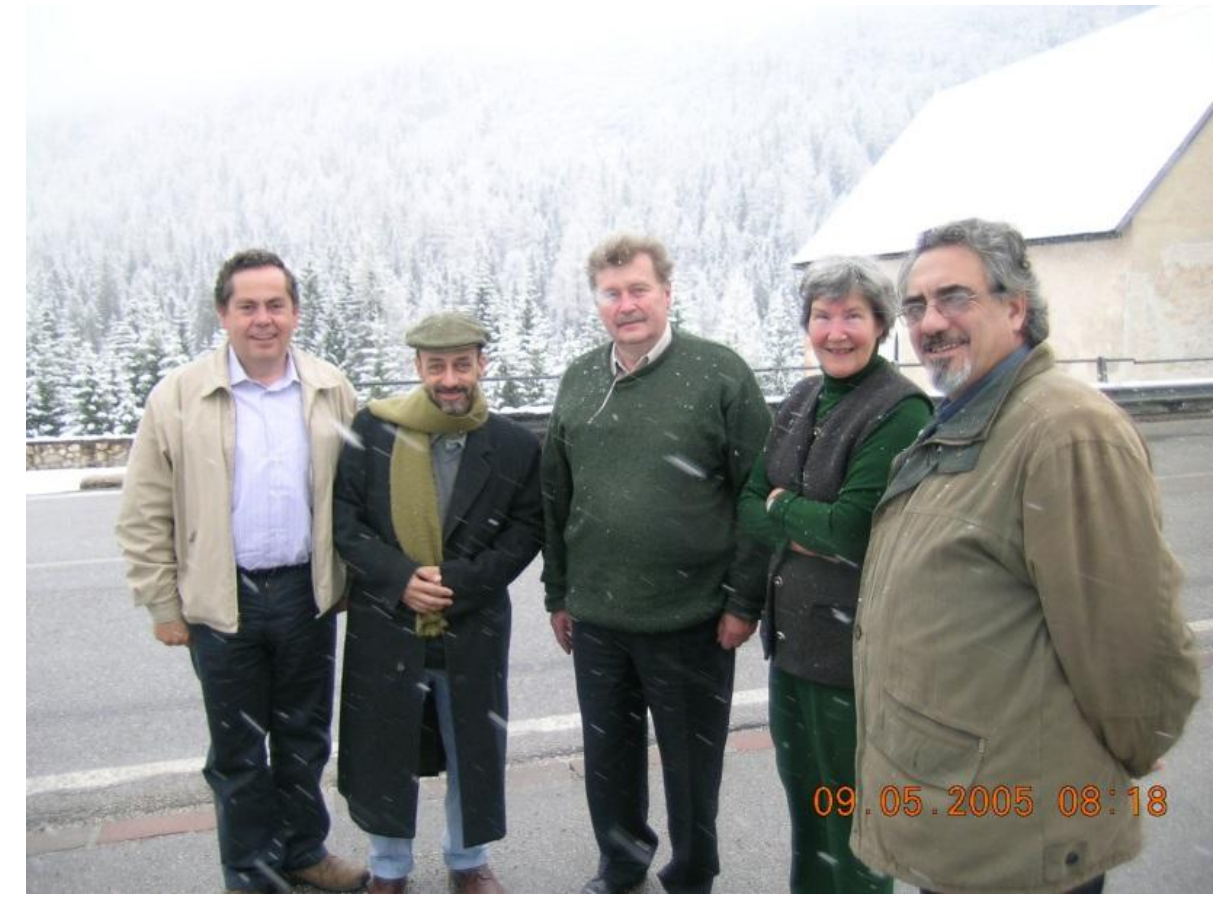

Neste caminho, Pedro Paulo me pediu que o fotografasse, "pois no Brasil não acreditariam que ele havia dirigido em uma estrada nevada.

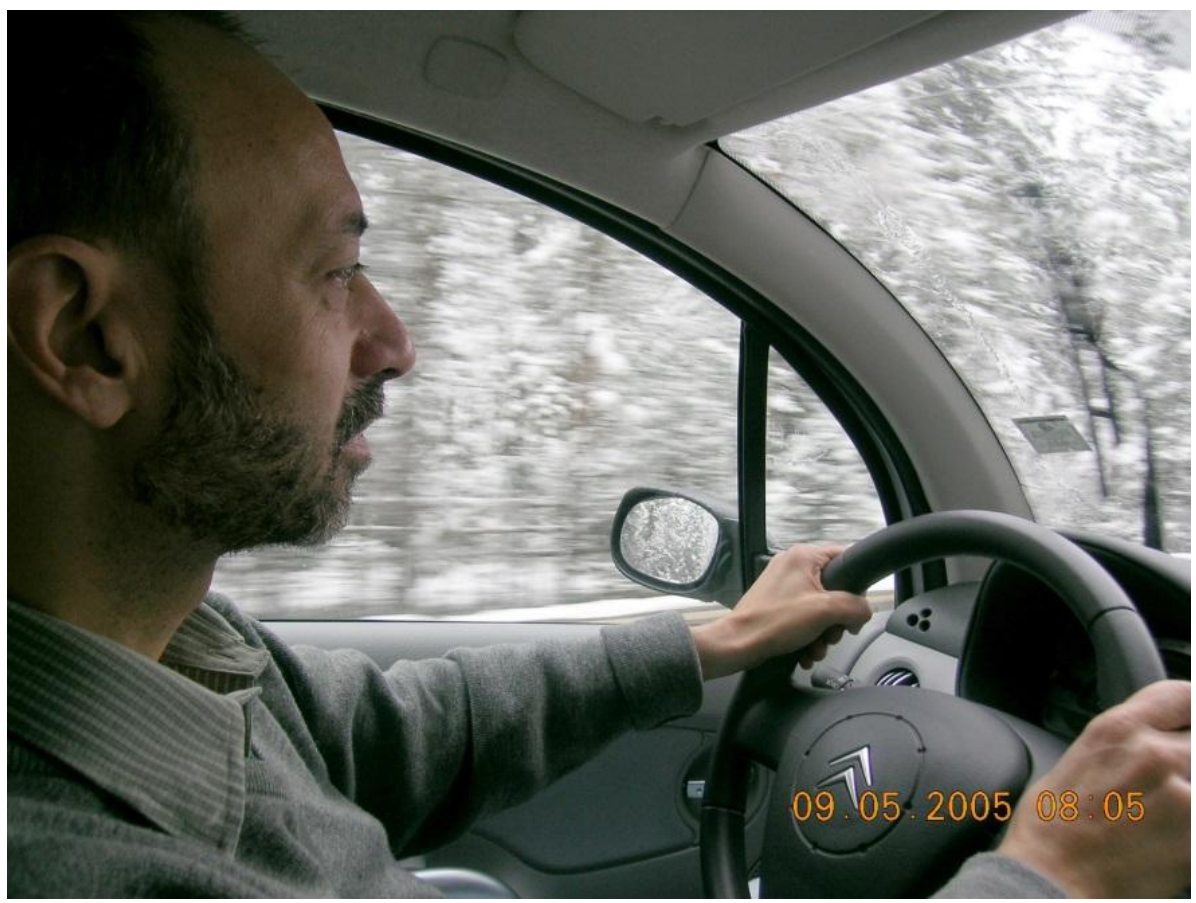

Outro importante marco de nossa relação ocorreu em minha viagem ao Brasil, em 2012. Cheguei convidado pela colega e amiga Margarida Maria de Carvalho com a intenção de falar sobre as "Raízes e evolução da alimentação europeia" para o curso de pós-graduação em História da 
Universidade Estadual Paulista, em Franca. Aproveitei para dar algumas palestras pelo país e a primeira foi em Campinas, em 12 de março, recémchegado de uma viagem que durou 26 horas desde Barcelona. Minha primeira palestra em Campinas teve como tema a qualidade do vinho que os romanos da Antiguidade bebiam. Por esta razão, gostaria de tratar de um tópico que apareces de maneira recorrente ao longo dos tempos, especialmente entre aqueles pesquisadores que não conhecem fontes literárias romanas e, acima de tudo, o processo pelo qual o vinho é obtido. A idéia é discutir que o envenenamento por chumbo, o plumbismo, foi a causa da loucura de alguns imperadores romanos e até mesmo da queda do Império².

Embora as primeiras descrições médicas de envenenamento por chumbo tenham aparecido na literatura médica clássica e que tanto os gregos quanto os romanos estavam conscientes do perigo representado pelo elemento químico ${ }^{3}$, a etiologia correta sobre o saturnismo não foi revelado até 1656, quando o alemão Samuel Stockhausen estudou a doença laboral sofrida pelos trabalhadores nas minas Rammelsberg na Baixa Saxônia 4 . Não foi a primeira vez que a doença apareceu nos tempos modernos. Já em 1616, Citoys, o médico pessoal do cardeal Richelieu, o descreveu, denominando-a Colicum Pictonum por fustigar a antiga região da Poitou ${ }^{5}$ desde 1572. Na verdade, a doença apareceu e desapareceu em muitos lugares da Europa e da América, por isso veio a ser chamado de muitas formas diferentes: Colicum pictonum, de Poitou, de

\footnotetext{
2 O saturnismo ou plumbismo é o envenenamento causado pela ingestão de chumbo, $\mathrm{o}$ problema pode causar trastornos mentais, físicos e até mesmo a morte. Causa anemia, alucinacões, ataques de locura, e danos neurológicos irreversíveis quando chega ao cérebro.

${ }^{3}$ Nicando de Colofón (s. II a.C.), em sua obra Alexipharmaca 2.74ss. falava do chumbo como um elemento "brilhante, branco, mortal, como o leite". Produzia espuma na boca, aspereza na língua e sequidão na garganta, arcadas, calafrios, delírios, etc.; Celso (s. I a.C.) De medicina, 5.27.12b considera a cerusa o "chumbo branco" entre os venenos; Paulo Aegineta (s. VII d.C.), De Re Medica Libri Septem, 3.43 (Sobre as cólicas): “Eu sou da opinião que essa cólica (...) tenha surgido na Itália, assim como em outras regiões do Império Romano, como uma infecção pestilenta, que en muitos casos acaba como epilepsia, e em varios tipos de paralísia das extremidades".

4 S. Stockhausen, Libellus de lithargyrii fumo noxio morbifico ejusque metallico frequentiori morbo vulgo dicto die Hüttenkatze, Goslar, 1656.

${ }^{5} \mathrm{~A}$ oeste da França, entre Poitiers e o Atlântico. A doença se espalhou pela região por mais de 60 anos e depois desapareceu, para, mais tarde, se espalhar em outras partes da França. F. Citoys, De novo et populari apud Pictones dolore colico bilioso diatriba, Paris 1616. Citoys notou que sua aparição, em Poitou, coincidiu com a visão de uma nova estrela na constelação de Cassiopeia, instrumentalizando a chance de considerar essa aparição como um castigo divino para um mundo pecaminoso.
} 
Devonshire, de Madri, da Normandia, de Caiena, cólica saturnina , metálicos, dos pintores, dos encanadores, vegetais das Índias, etc.

O conhecimento de que todas essas doenças foram causadas pelo mesmo motivo veio em 1696, quando Gockel provou que certos métodos utilizados para "corrigir" os vinhos deficientes estavam na origem do problema. Gockel chegou a tal conclusão após comprovar que num mosteiro onde os monges tinham a mesma dieta, aqueles que não bebiam o vinho "corrigido"se apresentavam com boa saúde, enquanto aqueles que bebiam foram acometidos com as dolorosas cólicas já conhecidas desde a antiguidade (Colica Pictonum) ${ }^{6}$. Na verdade, naquele ano, houve uma série de surtos de plumbismo, no sul da Alemanha, relacionados às condições climáticas, que impulsionaram, e políticas, que permitiram, a adulteração dos vinhos com a adição de "açúcar de chumbo", uma acetato de titânio ou litargírio. Substâncias que eram adicionadas aos vinhos defeituosos ou diretamente ao vinagre para vendê-lo como vinho. Como apresentado anos mais tarde pelo dicionário Fabre, citando Tanquerel: Mais aucune substance n'a plus fréquemment donné lieu à la colique saturnine que les vins frelatés avec le litharge ou la céruse. Toutefois, dit M. Tanquerel, depuis que des mesures de police furent prises pour découvrir la falsification, on ne vit plus de coliques épidémiques causées par les vins durs et acerbes ${ }^{7}$.

O primeiro estudioso a falar de intoxicação por chumbo no mundo romano foi o inglês Henderson, que ao tratar da adulteração dos vinhos consumidos pelas classes mais pobres, ocorrida em seu tempo, regressa também à época romana para demonstrar que já naquele momento os vinhos eram, igualmente, adulterados 8 . Outros autores, do mesmo modo, trataram o problema, como o austríaco Hofmann e seu discípulo alemão Kobert, que avançou com esta ideia singular referente ao saturnismo, que só ganhou força no século seguinte9. Assim, até 1965, a crença de que a

6 E. Gockel, "De vini acidi per acetum lithargyri cum maximo bibentium damno dulcificatione", Ephemerides (Misc Curiosa). Dec. III, Ann. 4, Obs 30, 1697, pp.77-85; Idem, Eine curiose Beschreibung dess an 1694, 95, und 96, durch das Silberglett versüssten sauren Weins und der davon entstandenen neuen und vormals unerhörten Wein-Krankheit, Ulm, 1697.

7 A. FABRE (ed.), Dictionnaire des dictionnaires de médecine français et étrangers ou traité complet de médecine et de chirurgie pratiques, par une société de médecins, Paris 1850, p. 74.

${ }^{8}$ A. Henderson (1824), History of Ancient and Modern Wines, London 1824, p. 338-339.

9 K. B. Hofmann (1883), "Die Getränke der Griechen und Römer vom hygienischen Standpunkte", Deutsches Archiv für Geschichte der Medizin und medicin, 6, 269ss.; K.B. Hofmann (1885), Das Blei bei den Völkern des Altertums; R. Kobert (1886), Ueber den Zustand der Arzneikunde vor 18 Jahrhunderten; R. Kobert (1909), "Chronische Bleivergiftung im klassischen Atertum", en P. Diegart (ed.), Beiträge aus der Geschichte der Chemie, 103-119. 
queda do Império Romano, a "loucura" de alguns de seus imperadores e a baixa taxa de natalidade da aristocracia romana ocorreram devido à mesma causa, o envenenamento por chumbo, não cresceu fortemente. Entretanto, Gilfillan em 1965, mais tarde Nriagu em 1983 e depois alguns outros ${ }^{10}$, consideraram que os romanos, especialmente suas classes dominantes, desconheciam os perigos do chumbo, sendo vítimas de sua própria ignorância, o que não é lógico ${ }^{11}$.

Os autores favoráveis a teoria apresentada levam em consideração duas razões principais de envenenamento: a utilização de encanamento de chumbo na rede de distribuição de água nas cidades romanas e o uso de caldeiras de chumbo para a fabricação do defrutum, o açúcar dos pobres romanos.

A primeira das causas, o uso de canos de chumbo no abastecimento de água das cidades romanas, expõe o envenenamento não apenas às classes dominantes, mas também a toda a população. Além disso, os romanos conheciam o problema, pois entende-se que eles estivam sempre alerta sobre a situação, como claramente referido pelo engenheiro e arquiteto Vitrúvio (Século I a C) 12:

[...] a água conduzida por canos de barro é muito mais saudável do que o que chega por tubos de chumbo, porque o chumbo é mais prejudicial para facilitar a presença da cerusa que, de acordo com o que se diz, é prejudicial ao corpo humano. Portanto, se o que gera chumbo é prejudicial, não há dúvida de que o chumbo também será prejudicial. Nós podemos fornecer o exemplo daqueles que trabalham com o chumbo, observando que eles têm uma pele completamente pálida. Quando o chumbo é derretido, o vapor que ele expande

10 S.C. Gilfillan, (1965) "Lead Poisoning and the Fall of Rome", Journal of Occupational Medicine, 7, 53-60; S.C. Gilfillan, (1990) Rome's Ruin by Lead Poison; J. O. Nriagu (1983), "Saturnine Gout Among Roman Aristocrats: Did Lead Poisoning Contribute to the Fall of the Empire?", New England Journal of Medicine, 308, 660-663; ; J. O. Nriagu (1983), "Occupational Exposure to Lead in Ancient Times", The Science of the Total Environment, 31(2), 105-116; ; J. O. Nriagu (1983), Lead and Lead Poisoning in Antiquity; ; J. O. Nriagu (1998), "Clair Patterson and Robert Kehoe's paradigm of 'Show me the data' on environmental lead poisoning". Environ. Res., 78, 71-78.

${ }_{11}$ Contrário a isso, pode-se ver na obra de Scarborough, que disse ser o trablho de Nriagu "tão cheio de falsas provas, mistificações, erros tipográficos e uma leveza flagrante em relação a fontes primárias que o leitor não pode confiar nos argumentos básicos do mesmo, "Chegando à conclusão de que o envenenamento por chumbo não era endêmico no Império Romano a ponto de causar sua queda. $\mathrm{O}$ mesmo, acreditam Waldron o Needleman: J. Scarborough, (1984) "The Myth of Lead Poisoning Among the Romans: An Essay Review", Journal of the History of Medicine, 39, 469-475; H.A. Wald Waldron (1973), "Lead Poisoning in the Ancient World", Medical History, 17, 391399; D. Needleman, L. NeEdLEMAN (1985), "Lead Poisoning and the Decline of the Roman Aristocracy", Classical Views, 4(1), 63-94.

12 VITRÚVIO 8.6.10-11. 
penetra em todos os membros do corpo e mina a energia do sangue. Consequentemente, não é aconselhável usar tubos de chumbo para conduzir a água se quisermos que ela seja saudável. A comida que consumimos a cada dia nos possibilita constatar que a água tem melhor sabor se for conduzida através de tubos de barro, porque todos, embora tenham suas mesas preparadas com copos de prata, usam recipientes de barro para preservar melhor o sabor e a pureza da água.

Além disso, os romanos não usavam torneiras, que cortam e paralisam a água corrente, de modo que dificilmente sofreram os efeitos de um contato prolongado com o chumbo. A confirmação disso é dada pela análise recente de isótopos de chumbo feitos nos sedimentos daquela época encontrados no fundo do rio Tibre e do vizinho Porto de Trajano: apesar de observar que a água transportada pelos tubos de chumbo continha pelo menos 100 vezes mais chumbo do que a água da chuva, os pesquisadores concluem que: "Lead pollution of 'tap water' in Roman times is clearly measurable, but unlikely to have been truly harmful"13.

A segunda suposta fonte de envenenamento de imperadores e aristocracia romana seria o consumo de defrutum. Mais precisamente, a ignorância do que é o defrutum e, acima de tudo, seus usos, levaram muitos autores modernos a pensar que os ricos romanos bebiam vinho que continha esse produto ${ }^{14}$. Nada está mais longe da realidade. Mas, para saber o que o defrutum realmente é e para o que serve, devemos primeiro saber que o fator mais importante na qualidade de um vinho é a quantidade de luz solar recebida pela uva. Se não houver sol o bastante, a uva não produz açúcares suficientes e, sem eles, a fermentação alcoólica criará um vinho com pouca estabilidade e com muitas possibilidades de sofrer problemas.

Em princípio, quanto maior a quantidade de açúcar no suco de mosto ou de uva, mais alto será o teor alcoólico do vinho. Da mesma forma, quanto maior essa riqueza, menor a probabilidade de o vinho ser picante ou avinagrado, ainda que esse risco ${ }^{15}$ não exista em vinhos acima de $16^{\circ}$. Portanto, para compensar os casos de maturação insuficiente das uvas ${ }^{16}$,

${ }^{13}$ H Delile, J. Blichert-Toft, J.Ph. Goiran, S. Keay, F. Albarède (2014),: "Lead in ancient Rome's city waters", Proceedings of the National Academy of Sciences, 111, 6.594-6.599.

14 Por ejemplo S. BHATTACHARJEE (2009), "A brief history of gout", International Journal of Rheumatic Diseases, 12, 61-63. O incluso C.M. Cipolla, Allegro ma non troppo, 1996, p. 6-7.

${ }^{15}$ L. Ibar (2002), Cómo se hace un buen vino, Barcelona, 159ss.

${ }^{16} \mathrm{O}$ amadurecimento excessivo consiste em todos os processos que tendem a aumentar a concentração de açúcar nas uvas. Tradicionalmente, esses processos foram dois: deixar os cachos, mesmo que maduros, na videira ou expô-los a luz, já cortados, estendendo-os por um certo tempo ao sol ou à sombra, pendurados em sisal ou quaisquer tipos de fios. 
os vinicultores sempre procuraram completar o fenômeno natural de maturação exaltando os fenômenos bioquímicos normais de maturação por amadurecimento excessivo da uva ou fazendo uma correção obrigatória para que ele adquira uma composição química próxima da obtida com uma boa maturação ${ }^{17}$.

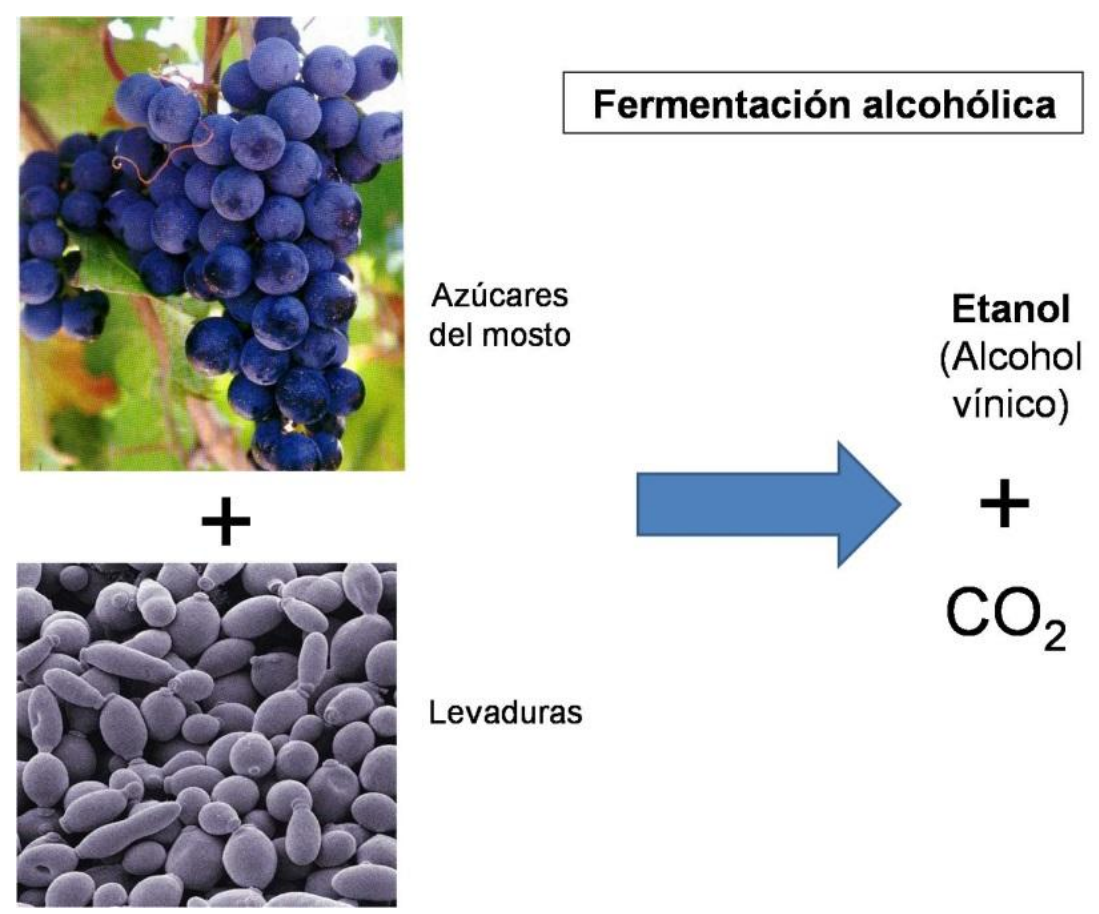

A operação citada acima é uma correção química da colheita, que consiste em aumentar o teor de açúcar do mosto. Este aumento, às vezes chamado de enriquecimento, pode ser realizado basicamente de três maneiras ${ }^{18}: 1$ ) por adoçamento (ou chaptalização), 2) por desidratação parcial do mosto de toda a colheita ou 3) por adição ao total da vindima de uma parte do mosto previamente desidratado. Em suma, essas correções são basicamente destinadas a obter bons vinhos de colheitas em condições precárias de amadurecimento. A este respeito, em 1905, Gayon disse:

\footnotetext{
17. Às vezes, quando a quantidade de açúcar no mosto é muito alta para fazer o vinho, é necessário eliminar parte do grau de glucometrico, isto é, adicionar água o mosto. Além da correção do nível de açúcar, existem outras correções importantes que, às vezes, devem ser feitas. Em especial em relação ao grau de acidez do mosto, artificialmente dando mais ou mneos acidez, dependendo do caso ou da necessidade.. 18 E. Ribéreau-Gayon, E. Penaud, P. Ribéreau-Gayon, P. Sudraud (1992), Sciences et techniques du vin. Traité d'oenologie. T. III: Vinifications, transformations du vin, Paris 1976 (= Tratado de enología. Ciencias y técnicas del vino. Tomo III: Vinificación. Transformación del vino, Buenos Aires 1992) 1992, 12-13.
} 
O açúcar, praticado em doses moderadas, com primeira qualidade, é uma operação legítima e recomendada, porque é susceptível de melhorar o vinho de forma muito sensível, facilitar sua conservação e aumentar seu valor comercial ${ }^{19}$

A mensagem de Columela tinha um significado semelhante mais de dezoito séculos antes, embora o romano dissesse isso em outras palavras:

Qualquer tipo de vinho que pode durar muito tempo sem curativos, pensemos que é o melhor e que nada deve ser misturado a ele, pois seu sabor natural pode ser alterado, pois o melhor de todos é aquele que pode agradar por sua própria natureza. Mas quando, devido a um defeito na região ou nas novas vinhas, o mosto é de má qualidade [...] vamos levar o mosto das tinas até os caldeirões de arrope $[\ldots]^{20}$

Dos três processos mencionados, o primeiro consiste na adição ao açúcar comum ou à sacarose ${ }^{21}$ e tem origem no médico francês e químico Jean Antoine Claude Chaptal (1756-1832), Ministro do Interior com o Conselho de Napoleão, Conselheiro de Estado e membro do Instituto Nacional da França e de numerosas academias e sociedades francesas ${ }^{22}$. A prática de chaptalização é usada atualmente e principalmente na França e na

19 U. Gayon, Préparation et conservation du vin, Bordeaux 1905, citado por E. RibéreauGayon, E. Peynaud, P. Ribéreau-Gayon, P. Sudraud (1992), Sciences et techniques du vin. Traité d'oenologie. T. III: Vinifications, transformations du vin, Paris 1976 (= Tratado de enología. Ciencias y técnicas del vino. Tomo III: Vinificación. Transformación del vino, Buenos Aires 1992) 1992, 11.

${ }^{20}$ Columela, Re Rustica, 12.19.2-3. Traducción de M. Villarejo y M. García-Denche para la edición del Ministerio de Agricultura (A. Holgado Redondo (ed.), Lucio Junio Moderato Columela, De los trabajos del Campo, Ministerio de Agricultura Pesca y Alimentación, Madrid 1988, 274).

${ }^{21}$ A sacarose não fermenta por si só e deve ser previamente transformada em frutose e glicose (os dois principais açúcares contidos na uva), uma transformação chamada inversão. Na prática, o potencial invertido dos catalisadores de levedura presentes na uva, que pode hidrolisar rapidamente a sacarose (um dissacárido) e convertê-la nos dois monossacarídeos já mencionados, é demonstrado: glicose e frutose (por E. Ribéreau-Gayon, E. Peynaud, P. Ribéreau-Gayon, P. Sudraud (1992), Sciences et techniques du vin. Traité d'oenologie. T. III: Vinifications, transformations du vin, Paris 1976 (= Tratado de enología. Ciencias y técnicas del vino. Tomo III: Vinificación. Transformación del vino, Buenos Aires 1992) 1992, pp. 12-13; L. Ibar (2002), Cómo se hace un buen vino, Barcelona, p. 65.

${ }^{22}$ Ele expos sua descoberta em um livro chamado Traité théorique et pratique sur la culture de la vigne, avec l'art de faire le vin, les eaux-de-vie, esprit-de-vin, vinaigres simples et composés. Ouvrage dans lequel se trouvent les meilleures méthodes pour faire, gouverner et perfectioner les vins et eaux-de-vie; avec xxi planches représentant les diverses espèces de vignes; les machines et instrumens servant à la fabrication des vins et eaux-de-vie. Publicado por Delalain hijos, Paris 1801. Provavelmente o primeiro escritor em viticultura e vinificação que trabalhou e baseou-se mais na evidência científica de seus dias do que a partir dos ensinamentos tradicionais. 
Alemanha, onde nem todos os anos as uvas recebem o sol de que necessitam.

O segundo processo consiste na adição ao total da colheita de uma parte do mosto previamente desidratado. Atualmente, este procedimento é realizado por qualquer método autorizado, diferente do fogo direto, de modo que sua densidade a $20^{\circ} \mathrm{C}$ não seja inferior a 1240, o que corresponde a cerca de $575 \mathrm{~g} / 1$ de açúcar (de acordo com a expressão antiga, cerca de $28^{\circ}$ Baumé) ${ }^{23}$. Pelo mesmo motivo que a adição de açúcar, a adição de mosto concentrado deve ser feita antes ou no início da fermentação ${ }^{24}$.

O terceiro processo, possível, é a desidratação parcial do mosto de toda a vindima. De acordo com os enólogos e o paladar moderno, esta operação não deve levar a uma redução de mais de $20 \%$ no volume inicial do mosto ${ }^{25}$, nem deve aumentar o nível alcoólico natural do mosto, inicial em mais de $2^{\circ}$; Isto visa a obtenção de produtos que possam fermentar normalmente sem dissolução.

A descoberta feita por Chaptal foi ignorada pelos romanos. No entanto, as fontes literárias nos permitem verificar que os romanos conheciam os outros dois procedimentos mencionados para a correção da colheita, embora o normal fosse que eles usassem o segundo, isto é, a desidratação do mosto até a obtenção do arrope. Na verdade, vários autores antigos nos fornecem dados suficientes para conhecer o modo como esses procedimentos eram realizados, com a variante que o único caminho conhecido na época romana para reduzir o mosto foi cozinhá-lo com fogo direto, já que não havia processos modernos de redução a vácuo, que impede o processo de caramelização do mosto.

\footnotetext{
${ }^{23}$ Os manuais modernos de enologia recomendam a obrigatoriedade, por exemplo, de uma quantidade de açúcar de 191,6 gr/l (que teóricamente daría un vinho de aproximadamente $11^{\circ}$ ), pode-se reduzir até $1 / 3$ de seu volume inicial até alcançar 575 gramas de açúcares por litro. Assim, os escritores modernos recomendam reduzir o mosto na mesma quantidade que os vinicultores romanos reduziram o deles (por exemplo, por E. Ribéreau-Gayon, E. Peynaud, P. Ribéreau-Gayon, P. Sudraud (1992), Sciences et techniques du vin. Traité d'oenologie. T. III: Vinifications, transformations $d u$ vin, Paris 1976 (= Tratado de enología. Ciencias y técnicas del vino. Tomo III: Vinificación. Transformación del vino, Buenos Aires 1992) 1992, 14-15).

${ }^{24}$ por E. Ribéreau-Gayon, E. Peynaud, P. Ribéreau-Gayon, P. Sudraud (1992), Sciences et techniques du vin. Traité d'oenologie. T. III: Vinifications, transformations du vin, Paris 1976 (= Tratado de enología. Ciencias y técnicas del vino. Tomo III: Vinificación. Transformación del vino, Buenos Aires 1992) 1992, 14-15.

${ }_{25}$ Por sua vez, entre os antigos, Columela aconselhou a redução de $10 \%$ do mosto de toda a vindima (Columela, Re Rustica, 12.20.8), enquanto Demócrito aconselhava reduzir até $20 \%$ (Geopónicas 7.4 ).
} 
As fontes latinas chamam estes mostos cozidos ou arropes basicamente com três nomes diferentes, que também mudam ao longo do tempo: defrutum, sapa e caroenum ${ }^{26}$. A única diferença entre eles é o grau de concentração de açúcar de cada composto, isto é, na quantidade de água que é conservada em cada um (ver um resumo na Tabela 1). De fato, tanto o defrutum como o sapa ou o caroenum são exatamente os mesmos: é um concentrado de suco de uva que os especialistas romanos recomendam fazer cozinhando o suco em grandes caldeirões de chumbo 27 .

\begin{tabular}{|l|l|l|l|}
\hline & Defrutum & Sapa & Caroenum \\
\hline Catón & Sin precisar. & Sin precisar. & --- \\
\hline Varrón & Reduce del 100\% al 33\% & Reduce del 100\% al 50\% & --- \\
\hline Columela & Reduce del 100\% al 33\% & Reduce del 100\% al 50\% & --- \\
\hline Plinio & Reduce del 100\% al 50\% & Reduce del 100\% al 33\% & --- \\
\hline Paladio & En cuanto se espesa & Reduce del 100\% al 33\% & Reduce del 100\% al 66\% \\
\hline Isidoro & Reduce del 100\% al 50\% & Reduce del 100\% al 33\% & Reduce del 100\% al 66\% \\
\hline
\end{tabular}

Tabela 1. Porcentagem da redução do mosto de acordo com diferentes autores latinos.

$\mathrm{O}$ arrope ou mosto reduzido, em suas diferentes variantes como o defrutum, sapa e caroenum, tinham muitos usos, mas os principais eram dois: primeiro, seu uso na vinificação para adicioná-lo às uvas que, não tendo tido bastante luz eram deficientes em glicose e, portanto, estavam em perigo de produzir vinhos deficientes. Em segundo lugar, como adoçante $^{28}$. De fato, desde a época romana e até o surgimento da beterraba açucareira, o arrope era sempre o açúcar dos pobres no sul da Europa, isso devido a seu preço ser mais baixo do que opções como o mel ou o açúcar de cana.

Portanto, voltando à possibilidade de os imperadores romanos e os aristocratas terem sido envenenados pelo consumo de vinho contaminado com chumbo, nada poderia estar mais longe da realidade. Como vimos, a teoria da vinificação romana exigiu que os vinhos fossem tão puros quanto possível e, como amostra, temos a citação de Columela

26 A. Aguilera Martín (2004), "Defrutum, sapa y caroenum. Tres nombres y un producto: arrope", en C. Carreras, A. Aguilera et alii, Culip VIII i les àmfores Haltern 70, Barcelona 2004, 120-132.

27 A. Aguilera Martín (2004), "Defrutum, sapa y caroenum. Tres nombres y un producto: arrope", en C. Carreras, A. Aguilera et alii, Culip VIII $i$ les àmfores Haltern 70, Barcelona 2004, 120-132.

28 A. Aguilera Martín (2004), "Defrutum, sapa y caroenum. Tres nombres y un producto: arrope", en C. Carreras, A. Aguilera et alii, Culip VIII i les àmfores Haltern 70, Barcelona 2004, 120-132. 
que mencionei antes, embora não seja a única. $\mathrm{O}$ arrope, de acordo com essa mesma teoria enológica, só deveria ser adicionada aos vinhos que precisavam de um enriquecimento em açúcares. Desse modo, o arrope foi o produto mais usado na falsificação e adulteração de vinhos romanos. E precisamente aqueles não eram o que as pessoas mais ricas costumavam consumir. Em suma, como Plínio, o Velho (14.130) disse:

Catón ordena que o vinho seja "preparado"(assim diz ele) sendo adicionada na quadragésima parte o licor de cinzas ou acrescentar uma libra e meia de sal e às vezes mármore esmagado, isso para se conseguir o equivalente a 20 ânforas. Ele, também, menciona o enxofre, mas de resina apenas a ser acrescentado por último. Acima de tudo adicionando ao vinho, que está começando a amadurecer, o mosto que ele chama de tortivo e que nós conhecemos como o líquido proveniente da última prensa. Sabemos também que os corantes eram adicionados para a melhor pigmentação do vinho, e assim ganhar corpo. Com tantas combinações, forçamos o vinho a agradar e admiramos a bebida ser prejudicial! Sendo a prova de que vai estragar, o fato de ele mudar a cor de uma folha de chumbo se colocado sobre ela ${ }^{29}$.

O mesmo, ainda que usando uma linguagem mais fictícia, disse Henderson 18 séculos depois, referindo-se ao mesmo problema ${ }^{30}$ :

There is (...) a certain fraternity of chemical operators, who work underground in holes, caverns, and dark retirements, to conceal their mysteries from the eyes and observations of mankind. These subterraneous philosophers are daily employed in the transmutation of liquors, and, by the power of magical drugs and incantations, raising, under the streets of London, the choicest products of the hills and valleys of France. They can squeeze Bourdeaux out of the sloe, and draw Champagne from an apple (...) the reduction of duty on Cape wines enables the adepts of the present day to employ, as occasion may require, a more substantial and convenient menstruum for their preparations, than that formerly used. By mixing these wines with the lees of other kinds, and tinting and compounding them with various drugs, they endeavour to counterfeit the more costly vintages of Spain and Portugal, and even of France. (...) The high impost on the choicer wines, however, holds forth so strong a temptation to embark in this disreputable trade, that we must lay our account with its continuance, until the return to more moderate and equal rates shall remove the causes from which it has chiefly sprung".

Alguns vinhos, é claro, que não beberiam nem os sirs e lords do império britânico. Of course!

${ }^{29}$ Um compêndio bizantino do século IX, o Geoponics, descreve o processo (7.15.17-18): "fabrica-se uma folha de chumbo e cola-se , com cera, na tampa de uma ânfora, antes de fechá-la. Em quarenta dias, abre-se o recipiente: se a folha não estiver inalterada, o vinho está saudável, mas se parecer esbranquiçada, o vinho estragou".

30 A. Henderson, History of Ancient and Modern Wines, London 1824, p. 338-339. 